\title{
Cognitive emotional consequences of male infertility in their female partners: a qualitative content analysis
}

Fatemeh Zahra Karimi ${ }^{1}$, Ali Taghipour ${ }^{2}$, Robab Latifnejad Roudsari ${ }^{3}$, Seyed Ali Kimiaei ${ }^{4}$, Seyed Reza Mazlom ${ }^{5}$, Maliheh Amirian ${ }^{6}$

${ }^{1}$ Ph.D. Student of Reproductive Health, Student Research Committee, School of Nursing and Midwifery, Mashhad University of Medical Sciences, Mashhad, Iran

${ }^{2}$ Ph.D. Associate Professor of Epidemiology, Health Sciences Research Centre, Department of Biostatistics and Epidemiology, School of Health, University of Medical Science, Mashhad, Iran

${ }^{3}$ Ph.D. Associate Professor of Reproductive Health, Research Centre for Patient Safety, Department of Midwifery, School of Nursing and Midwifery, Mashhad University of Medical Science, Mashhad, Iran

${ }^{4} \mathrm{Ph} . \mathrm{D}$. Associate Professor, Department of Education, Faculty of Education and Psychology, Ferdowsi University of Mashhad, Mashhad, Iran

${ }^{5}$ M.Sc. of Nursing, Lecturer, Evidence-Based Care Research Center, School of Nursing and Midwifery, Mashhad University of Medical Sciences, Mashhad, Iran

${ }^{6}$ M.D., Assistant Professor of Obstetrics \& Gynecology, Women's Health Research Center, School of Medicine, Mashhad University of Medical Sciences, Mashhad, Iran

\section{Type of article: Original}

\begin{abstract}
Introduction: Infertility, as a global phenomenon and one of the most important issues of reproductive health, affects women more often than men, even when the infertility is due to a male factor. The purpose of this study was to explore the cognitive emotional experiences of women faced with male infertility.

Methods: This qualitative study was conducted in 2014-2015 in Mashhad, Iran. The perceptions and experiences of healthy women whose husbands were diagnosed with primary male factor infertility were investigated using a qualitative content analysis approach. Participants were selected through purposeful sampling, and data collection was conducted using in-depth semistructured interviews. Data were analyzed using conventional content analysis with MAXqda software. Study rigor was verified via criteria proposed by Lincoln and Guba.

Results: One main theme emerged through analysis entitled "cognitive emotional reactions confronting infertility diagnosis" with sub-themes of cognitive emotional reactions when confronted with male infertility diagnosis with subthemes of disbelief and denial, fear and apprehension, suffering and emotional distress, disappointment, frustration, confusion, and joy.

Conclusion: The diagnosis of male infertility was associated with important emotional cognitive consequences for their female partners. Emotional support, providing new insights into how to treat the issue, and trying to shorten the process of diagnosis are necessary for these women. This kind of support could reduce the psychological effects of confrontation with the diagnosis of male infertility, including social insecurity for women.
\end{abstract}

Keywords: women, male infertility, content analysis, cognition, emotional

\section{Introduction}

Infertility is a global problem $(1,2)$ and is considered one of the most important issues of reproductive health (3). The World Health Organization (WHO) considers infertility as a disease and its prevalence as an indicator of reproductive health in women of reproductive ages of 15-49 years. Therefore, addressing this issue has been raised as a health priority (4-6). According to previously obtained data, infertility affects $10 \%$ to $15 \%$ of couples in the

\section{Corresponding author:}

Associate Professor Dr. Ali Taghipour. Department of Biostatistics and Epidemiology, School of Health, University of Medical Science, Mashhad, Iran. Tel: +98.5138591512, Email: TaghipourA@mums.ac.ir

Received: October 05, 2015, Accepted: November 01, 2015, Published: November 2015

iThenticate screening: October 27, 2015, English editing: November 06, 2015, Quality control: November 08, 2015 (C) 2015 The Authors. This is an open access article under the terms of the Creative Commons Attribution-NonCommercialNoDerivs License, which permits use and distribution in any medium, provided the original work is properly cited, the use is non-commercial and no modifications or adaptations are made. 
world, and its prevalence is increasing; thus, it has become a social concern $(6,7)$. In studies conducted in Iran, the prevalence of primary infertility was estimated at $24.9 \%$ (8). Infertility is not just a medical problem but also a crisis of social life (9-12). It can influence interpersonal, marital, and social relationships and cause significant emotional and psychological damage $(11,13,14)$. The path that the infertile couple must take is not an easy one (15). It results in the occurrence of a wide range of emotional and physiological disorders $(11,16-19)$, which may be destructive (20) and have a damaging and lasting impact on their lives (19). Although both men and women experience this problem, it affects women and men in different forms (21-23). Even in male infertility, which is the cause of more than half of all infertility cases worldwide, women endure the main burden of this issue (24, 25). Because having children is more important for women, they are typically more involved in the follow-up, diagnosis, and treatment processes. Furthermore, social pressure is more focused on women than on men. In Iran, this issue has more complicated consequences, for the reason of parents and relatives' role in the couple's life (26-28). With any sort of delay in becoming pregnant, concerns, curiosity, pressures, and interference of others start, and individuals typically encounter significant psychosocial stress, which leads to numerous forms of psychological disturbances (29-32). Moreover, studies have shown that, when the cause of infertility is the man, he will be distressed and show more emotional responses toward infertility. However, women, whether or not they are the cause of infertility, typically experience mental breakdowns (33). Some researchers have indicated the existence of psychological problems in both partners; however, despite its impact on both sexes, it seems that women experience higher levels of stress and emotional turmoil (34). The aforementioned argument justifies the importance of investigating the consequences of infertility. In Iran, although studies have been conducted on infertility, no study has been reported on the emotional problems of women who are dealing with their spouse's infertility. Despite many psychological problems that these women are faced with and being placed at the heart of the problem, less attention has been paid to their issues by health authorities. Therefore, people who live with this problem, suffer from severe psychological damage (3, 14, $21,29,35,36)$. Unfortunately, little information exists on the psychological consequences of infertility in women whose husbands suffer from male factor infertility. Addressing the problems of this group and considering them in health planning and policy-making is of great importance. In order to help these women, their problems, concerns, and understanding of spouse's infertility, then, should be identified. To meet this goal, the qualitative methods are suited to be adopted for exploring the psychosocial aspects of infertility. Qualitative research methods must respond to research questions regarding psychosocial phenomena due to the complexity of these phenomena and lack of information (10). Due to the above reasons, this study aims to explore the cognitive emotional implications of confronting women with the male infertility diagnosis of their spouses.

\section{Material and Methods}

\subsection{Research design and setting}

This was a qualitative study carried out using conventional content analysis. The study included healthy wives of infertile men who were referred to the Milad Infertility Center of Mashhad as well as women who were identified through health care clinics of Mashhad.

\subsection{Sample size and sampling methods}

In qualitative studies, most sampling is performed with maximum variation through purposeful sampling with a wide range of changes in the desired dimensions (37). Therefore, purposive sampling with maximum variation (regarding age, occupation, education, and duration of infertility) was performed. The first participant was selected, based on inclusion criteria, from those who provided rich information and had the ability to communicate and the willingness to provide their information. This sampling procedure was continued until data saturation; to the extent that new data were not obtained from the interviews. Because the number of participants is determined by the depth of data needed, and, when data saturation is achieved, the number of participants becomes sufficient. Data saturation occurs when the sampling does not provide any new data.

\subsection{Selection criteria}

\subsubsection{Inclusion criteria}

Iranian women, whose husbands were diagnosed with primary infertility and had the ability to understand and speak Farsi, were able to express their feelings, emotions, and experiences and had passed at least one year since their marriage was entered into the study.

2.3.2. Exclusion criteria

The exclusion criteria were women having children or stepchildren and had experienced marital breakdown or remarriage. 


\subsection{Instruments and data collection}

For data collection, semistructured interviews were used. This type of interview is used in qualitative research due to its depth and flexibility. This type of interview gives participants an opportunity to fully explain their experience of the phenomenon. Therefore, in this study, semistructured interviews were used to obtain in-depth and detailed data. Interviews began with open questions based on the interview guide. Questions in the interview guide were focused on the subject areas that had to be covered and the research line that had to be pursued. Then, they were followed by probing questions to achieve greater clarity $(37,38)$. In case of women's willingness to participate in the study, the arrangement was made regarding the time and place of the interview. During the interview, the researcher introduced herself and explained the objectives of the study and obtained an informed consent to record interviews with a recorder. Participants were also assured of the confidentiality of their experiences. The interview began with general questions and establishing appropriate relationships and gaining the women's trust. Then, the participants were asked to explain their experiences of their spouse's infertility. The subsequent questions were based on the responses of the participants and focused more on the important issues. In this study, the researcher was flexible toward the content of the responses of the participants and nonverbal cues. If, during the interview, the participants felt stressed, they were given the opportunity to relax and regain their composure. At the end of the interview, participants were asked to discuss unresolved issues. Finally, after acknowledgement of their participation in the interview, they were informed of the possibility of subsequent interviews. The researcher's phone number was provided for the participants for follow-up questions regarding the process of data collection and to be in contact with the researcher.

\subsection{Research ethics}

It was approved by the research ethics committee of Mashhad University of Medical Sciences, Mashhad, Iran. Informed consent was obtained from all participants.

\subsection{Data analysis}

Data analysis was conducted concurrently with data collection using conventional content analysis with MAXqda software (version, 2010). At the end of each interview, the recorded interviews were transcribed verbatim using a computer. To gain full insight and understanding of the phenomenon under study, the interviews were listened to and the typed text was reviewed several times. Then, the text was divided into meaning units, which consisted of a group of words related to the same meaning. The process of data reduction continued with labeling meaning units with codes. The codes were compared based on their similarities and differences and categories developed. Then, themes and subthemes emerged via linking the underlying meanings of categories through inductive analysis. After careful study and analysis of the text of each interview, the next interview was planned. For most participants, the interviews lasted approximately between 55 to 90 minutes. Study rigor verified via criteria proposed by Lincoln and Guba: spending enough time to collect and analyze data in order to gain a deep understanding of the phenomenon, reviewing the process of analysis by the research team, establishing a desirable relationship with the participants to conduct in-depth interviews, long-term involvement with the data, repeated reading of the interviews, frequent review and correcting of coding, and reviewing the different stages of the analysis in frequent meetings by the research team. To this end, interviews, codes, and extracted categories and themes were presented to several experts who were familiar with qualitative research; they were then asked to examine the coding and analysis and provide the necessary feedback. The different views in conceptualization were discussed and agreed upon. For the use of a variety of sources, data were collected from different groups and different places. Moreover, the participants reviewed the data, and experts and external reviewers analyzed and recorded and evaluated the different stages.

\section{Results}

\subsection{Sociodemographic characteristics}

In this study, 19 interviews were conducted with 14 women. Some women were interviewed more than once. Participants were aged 27-59 years; their mean age was 36.14 years. The duration of infertility ranged from 2 to 42 years with a mean of 13.35 years (Table 1$)$.

\subsection{Cognitive emotional reactions when confronted with male infertility diagnosis}

One main theme emerged through analysis, including cognitive emotional reactions when confronting male infertility diagnosis with subthemes of disbelief and denial, frustration and confusion, fear and apprehension, suffering and emotional distress, and disappointment and joy. The theme and subthemes are shown in Table 2. The diagnosis of male infertility is one of the most critical stages of dealing with the husband's infertility and has created 
many challenges for women. Most participants had experienced numerous emotional cognitive traumas, which are addressed in the following section.

Table 1. Characteristics of Participants

\begin{tabular}{|l|l|l|l|l|}
\hline Participants & Age (year) & Education & Job & Duration of Infertility (Year) \\
\hline 1 & 33 & Guidance school & Employed & 12 \\
\hline 2 & 49 & High school & Employed & 33 \\
\hline 3 & 35 & University & Employed & 10 \\
\hline 4 & 59 & Illiterate & Housewife & 42 \\
\hline 5 & 28 & University & Employed & 2 \\
\hline 6 & 35 & Elementary school & Housewife & 11 \\
\hline 7 & 44 & High school & Housewife & 23 \\
\hline 8 & 41 & Illiterate & Housewife & 7 \\
\hline 9 & 27 & University & Employed & 9 \\
\hline 10 & 32 & Elementary school & Housewife & 9 \\
\hline 11 & 35 & Elementary school & Housewife & 3 \\
\hline 12 & 29 & University & Employed & 8 \\
\hline 13 & 30 & High school & Housewife & 14 \\
\hline 14 & 29 & High school & Housewife & 4 \\
\hline
\end{tabular}

Table 2. Extracted Theme and Subthemes

\begin{tabular}{|l|l|}
\hline Theme & Subtheme \\
\hline Cognitive emotional reactions confronting & Disbelief and denial \\
\cline { 2 - 2 } with male infertility diagnosis & Fear and apprehension \\
\cline { 2 - 2 } & Suffering and emotional distress \\
\cline { 2 - 2 } & Disappointment \\
\cline { 2 - 2 } & Frustration and confusion \\
\cline { 2 - 2 } & Joy \\
\hline
\end{tabular}

\subsubsection{Disbelief and denial}

Some women, when faced with the unexpected news of infertility, are in disbelief or denial. The participant's statements regarding the moment they found out about their husband's infertility are presented as follows: Participant 1 stated: "When I took my husband's test to the doctor, she told me that he does not have any sperm ... I was just staring at her." Participant 9 stated: "When the doctor saw the spermiogram result, he said this is very low, as soon as he said that my heart just dropped." A participant with four years' history of infertility was perplexed and stated: "My husband and I were shocked ... I was just listening ... I had a lot of stress ... I was thinking that we could never have children..." (Participant 14). Participant 7 also said: "I was shocked and surprised when I heard his diagnosis. I never thought that such a thing would happen to me." Denial and rejection of male infertility diagnosis was a subcategory that emerged from the data. A participant's reaction when faced with male infertility diagnosis was: "I told myself that this cannot be true; any way I have to have a child by this time next year" (Participant 9). Participant 3 stated: "When the doctor told me that my husband was infertile and we could not have children, I said have you come from God that you can say we cannot have children?"

3.2.2. Frustration and confusion

Some women reported that, at the moment of the doctor's diagnosis of male infertility, they did not understand what was happening. Not expecting this outcome or the importance of this diagnosis may be the cause of confusion when faced with the initial diagnosis. In this respect, Participant 5 said: "I felt speechless when the doctor told me that my husband was infertile." Participant 11 said: "We did not know what this disease was ..."

3.2.3. Fear and apprehension

Some factors that women mentioned during interviews were signs of fear following the male infertility diagnosis. This included fear of disturbing the peace in their lives, separation, and how the husband and family would react to the male infertility diagnosis. In this respect, Participant 6 stated: "I was afraid ... I thought that this might cause us to separate." Other concerns of the women were how to inform friends and relatives of the infertility diagnosis of the husband and how they will react. Participant 14 said: "What could I tell the relatives? What would they say? If they 
say anything to me, we will have an argument." Many women, especially those married to men recently diagnosed with male infertility, were concerned about the disruption of their normal life routine. In affirmation of this, Participant 2 said: "I realized that this life will not be the same anymore ... that comfortable and carefree life will not be the same now."

3.2.4. Suffering and emotional distress

Being informed of the male infertility diagnosis, imagining the end of joy that they had in life, the sadness of the husband of being diagnosed, and how to inform their relatives and families of the infertility were painful and distressing experiences that were frequently reported by women. A participant with four and half years of experience of infertility stated with a sad tone: "When I found out, I was very upset. My heart was broken. It was like I had lost someone. I cannot describe how I felt" (Participant 9). In this respect, Participant 4 stated: "I was upset the first time the doctor told us that my husband does not have sperm." Participant 5 noted: "I was upset that we had this problem." Participant 14 also said: "The test results showed that we had zero possibility. I got so upset, my heart was broken." Participant 2 remarked: "I was depressed, lethargic, sad, and hopeless ... I was just crying ... I was upset that those wonderful days that we had together were over now." Some women cried following the male infertility diagnosis. In this respect, Participant 1 stated: "The doctor looked at me and said that we cannot get pregnant and the possibility was zero. My heart was broken. I started to cry; nothing was important for me anymore. I was just crying." Participant 12 said: "I was upset ... I started to cry. I could not stand it anymore."

\subsubsection{Disappointment}

Many women mentioned hopelessness as an important effect of the infertility diagnosis, especially untreatable infertility, on their mental status. Disappointment was mostly experienced suddenly and after hearing the diagnosis of infertility or untreatable infertility. On this subject, Participant 9 said: "After finding out about my husband's infertility, I was $90 \%$ hopeless. It was like when you have a relative in a coma, and they tell you that his heart is only working $5 \%-10 \%$ and his hope for survival is only $10 \%$. You have as much hope as his heart is beating." Participant 11 also said: "I was really hopeless ... we can't have children, and I won’t get pregnant."

3.2.6. Joy

Some of the women felt happy when they were informed of the male infertility diagnosis because they were no longer under pressure from their families. Participants 14 stated: "I was happy that no one could rebuke me; my husband could not rebuke me that I could not get pregnant. They always told me that I was thin and weak; I was happy to tell my sister in law because she always reproached me." Participant 3 noted: "I thanked God that I was not the problem. He was the problem, and he was always blaming me. Now I could tell them that he was the problem not me."

\section{Discussion}

Women who participated in this study differed in age, educational level, occupation, duration of marriage, and cause of infertility but had all experienced living with infertile husbands. In the present study, psychological consequences were categorized into one theme of cognitive emotional reactions when faced with the male infertility diagnosis. Most women participating in the study emphasized the psychological trauma they experienced due to the infertility diagnosis of their husbands. This period was different for the participants and had diverse psychosocial factors. It included fear and concern and the burden of negative behavioral and psychological effects of the society. . At this stage, the participants feel and experience a period of social and psychological pressure. Although infertility is important for the couple (15), studies have shown that the negative effects of infertility were higher for women than for men (21-23). Savadzadeh stated that if attempts to get pregnant fail, it can become a destructive emotional experience for the couple, but infertility, often, imposes a heavy burden on the women (39).

Findings of this study showed that the diagnosis of male infertility is one of the most critical stages of dealing with the husband's infertility. It seems that becoming aware of infertility is the cause of mental breakdown. The day of the male infertility diagnosis was a day that the women would not forget. Most of the participants expressed their fear, distress, and astonishment when they heard the diagnosis. For most people, the ability to reproduce is a fundamental issue in life. Accordingly, the inability to have a child is stressful, causing confusion in life $(9,10,26$, 40). Connolly et al. concluded, in their study, that male infertility factors cause greater mental breakdown for both men and women, but its intensity is less in men than in women $(29,41)$. Newton reported that there were more concerns regarding male infertility compared with unidentified causes of infertility and female infertility (22).

In this study, during the stage of male infertility diagnosis, different and sometimes contradictory reactions were observed in women, including disbelief and denial, intensified fear and concern. As previously noted, in the response to the diagnosis of male infertility, women were in denial because they were faced with an unexpected 
phenomenon. They were shocked and stunned, and they even denied the problem. Among the most important factors that caused fear in women, when diagnosed with male infertility, was imagining that they will not have the normal and calm life they had and their husbands will not be the same. After being informed of male infertility diagnosis, the women experienced feelings of sadness, depression, and despair, especially newlyweds, because these conditions lead to feelings of insecurity and fear due to their impact on life and marital instability. The diagnosis of infertility reduces or even eliminates the hope to have children. According to women, this pain is mutual, and it is not important whether the cause is female or male infertility. In addition, young people, even after marriage, are still under the influence of their families; therefore, infertility is not just a private matter between the husband and wife. It is a matter that involves several other people (family, the infertile person, the spouse, spouse's family and friends) $(27,36,42)$.

Most participants in this study mentioned fear. It was important for the researcher to understand the scope and depth of this concept. Thus, fear of the unpleasant reactions of others and the stigma of infertility are among the main concerns of women participating in this study. Social pressure and waiting for the women to get pregnant was mostly focused on the wife; following the delay in pregnancy, the women are the ones who experience infertility stigma. From normal women, they are turned into defective women. It seems that, even when the person does not experience the infertility stigma, the fear of such reactions will typically torment a woman. From the perspective of these women, regardless of the cause of infertility, people blame the woman for the delay in childbearing and women were typically accused of infertility. Studies by Tabong and Mumtaz also noted that the reactions of others will place more pressure on women $(35,36)$. The husband and his family being influenced by peoples' comments about female infertility, the possibility of conflicts, and family controversy followed by separation is a signifcant factor that influenced the fears of women following delay in pregnancy. Mohammadi has suggested that women typically feel responsible for every bad thing that happens, and, as a result of this responsibility, they suffer more damage (43). In analyzing this perspective, numerous factors in highlighting of the role of women and seeing them as the cause of infertility in Iran can be mentioned (44). It must be acknowledged that pregnancy is of greater importance to the women themselves (44), and any delay in the signs of pregnancy are typically unacceptable for them (35) because, for most women, becoming a mother is one of the aspects of their feminine identity and fostering their gender role. They believe that a woman's status in society depends on having children; therefore, by losing this opportunity, they typically suffer psychological, personality, and social damages $(22,26,29,32,35)$. Community pressure regarding fertility is focused more on women than on men. Expectations to be fertile are more focused on women than on men. Therefore, women are blamed more than men $(15,32)$. Gibson also states that, in addition to the women's feeling of responsibility of infertility, the husbands also blame the women (21). These findings suggest that, from the social perspective, regarding infertility, regardless of its cause, the couple typically both blame the woman. In fact, the phenomenon of infertility is a subject for which clear social boundaries cannot be defined. Hence, everyone, even nonfamily members, think that they have the right to judge. Even strangers break these boundaries and allow themselves to make judgments $(15,45)$. The women were often responsible for informing the husband of their infertility, which showed the effort and involvement of women in pursuing the cause of infertility. How to give the news was uncomfortable for women. Crying was one of the reactions of women when they were informed of the male infertility or it being untreatable. Crying probably helps women at such critical moments. Many other studies have introduced infertility an unpleasant experience, especially for women, and have suggested that the suffering and pain of dealing with infertility is much stronger and deeper in women than in men. Women have shown to be more vulnerable to this phenomenon $(46,47)$. Researchers believe that, although stress caused by any source has more pressure on women's lives, the stress of infertility has more negative pressure on women (48). Overall, the results of studies conducted in Iran indicated that most infertile individuals encounter unpleasant reactions from their social environments $(39,40)$. Therefore, in Iranian culture, the social pressure to have children and social reactions toward this group of people in society are the underlying causes of physical and psychosocial problems, especially for women $(49,50)$. This condition is actually the transference of a private pain to a socially evident pain, and this pain is more exasperating than the pain of infertility (51). In other words, infertility is a social phenomenon. Infertility not only involves the wife and the husband, it also includes their families and friends. Therefore, infertility is one of the worst experiences in life, and the social background and conditions of the couple can also affect it, thus transforming it into a personal crisis $(49,52)$.

Some limitations of this study included difficulties in accessing an affordable and relaxed environment for the interviews, the tendency for secrecy, women's unwillingness to express some of their experiences, and the dissatisfaction of some of the participants with recording of interviews due to the privacy issues of infertility, 
resulting in the prolonged process of data collection. The researchers tried to provide explanations and reassurance for participants to maintain the confidentiality of interviews in order to overcome this problem.

\section{Conclusions}

The findings of this study demonstrate that diagnosis of male infertility is a life crisis, thus leading to serious emotional and psychological trauma in women. It also is associated with receiving social pressure from others, especially the spouse's family. Therefore, it is recommended that this issue be considered as a high-risk psychological circumstance for women. They should be under emotional and psychological care at early stages, even before the announcement of infertility. In these circumstances, it can be expected that access to counseling services will decrease their mental problems when faced with the male infertility diagnosis. Therefore, it is hoped that, by using the results of this study, counseling services can be designed specifically for them. These findings emphasize the need for proving holistic health care for women and their families in the course of their crisis. Awareness of these experiences can provide the health care team with a more comprehensive understanding of the issues that women are faced with. Therefore, this study makes a significant contribution to improve the delivery of services. These findings also indicate the need for educating families of the couples and providing social protection for women in order to create a more positive experience for women when they are faced with this crisis. Finally, further research on the consequences of the male infertility diagnosis in men, women, and their families is recommended. One strength of this study is that it is the first study in this field in Iran.

\section{Acknowledgments:}

This article was extracted from the main author's postgraduate thesis, which has been approved by Mashhad University of Medical Sciences, Mashhad, Iran (Code: 930099). The authors express their gratitude to the vice chancellor for research, Mashhad University of Medical Sciences, Mashhad, Iran.

\section{Conflict of Interest:}

There is no conflict of interest to be declared.

\section{Authors' contributions:}

All authors contributed to this project and article equally. All authors read and approved the final manuscript.

\section{References}

1) Macaluso M, Wright-Schnapp TJ, Chandra A, Johnson R, Satterwhite CL, Pulver A, et al. A public health focus on infertility prevention, detection, and management. Fertil Steril. 2010; 93(1) :1-10. PMID: 18992879

2) Latifnejad Roudsari R, Rasolzadeh Bidgoly M,Mousavifar N,Modarres GHaravi M. The effect of collaborative counseling on perceived infertility-related stress in infertile women undergoing IVF. IJOGI. 2011; 14(4) :22-31.

3) Latifnejad Roudsari R, Karami Dehkordi A, Esmaili H, Mousavifar N , Agha Mohamadian Sherbaf H. The relationship between body image and marital adjustment in infertile women. IJOGI. 2011; 14(6):9-19.

4) Johansson M. Life after Terminated IVF- experience and quality of life among men and women. Geson Hyltetryck, Gothenburg, Sweden.2010.

5) United Nations General Assembly ,United Nations Population Information Network,UN Population Division, Department of Economic and Social Affairs, the UN Population Fund (UNFPA). Report of the International Conference of Population \& Development (ICPD). New York: UN. Cairo: 1994. Available from: http://www.un.org/popin/icpd/conference/offeng/poa.html

6) Sciarra J. Infertility: an international health problem. Int J Gynaecol Obstet. 1994; 46(2): 155-63. doi:10.1016/0020-7292(94)90230-5, PMID: 7995454

7) Fritz MA, Speroff L. clinical Gynecologic Endocrinology and Infertility .8th ed, 2010 Lippincott Williams \& Wilkins.

8) Behboodi - Moghadam Z, Salsali M, Eftekhar-Ardabily H, Vaismoradi M, Ramezanzadeh F. Experiences of infertility through the lens of Iranian infertile $\mathrm{n}$ women: A qualitative study. Japan Journal of Nursing Science .2012.doi: 10.1111/j.1742-7924.2012.00208.x

9) Johansson M, Berg M. Women's experiences of childlessness 2 years after the end of in vitro fertilization treatment.Scand J Caring Sci. 2005; 19(1): 58-63.PMID: 15737167

10) Dyer SJ, Abrahams N, Hoffman M, van der Spuy ZM. Leave me as I cannot have children': women's experiences with involuntary childlessness. Hum Reprod. 2002; 17(6):1663-8. PMID: 12042295 
11) Tuzer V, Tuncel A, Goka S, Dogan Bulut S, Yuksel FV, Atan A, Goka E. Marital adjustment and emotional symptoms in infertile couples: gender differences. Turk J Med Sci. 2010; 40 (2): 229-37. doi:10.3906/sag-0901-17

12) Faramarzi M, Pasha H, Esmaelzadeh S, jorsarai GA, Aghajani Mir MR, Abedi Sh. Is coping strategies predictor of anxiety and depression in couple infertile? Health. 2013. 5(3A): 643-49. doi: 10.4236/health.2013.53A085

13) Greil AL, Slauson-Blevins K, McQuillan J. The experience of infertility: a review of recent literature.Sociol Health Illn. 2010; 32(1): 140-62. doi: 10.1111/j.1467-9566.2009.01213.x.

14) Grinion P E. The biopsychosocial stress of infertility: grappling wit the ethical and moral concerns vis- $\mathrm{A}-$ visassisted reproductive technologies. North American Association of Christians in Social Work. 2005. Available from: http://www.nacsw.org/Publications/Proceedings2005/GrinionPInfertility.pdf

15) Ktral D. Causes of stress in the family. Translator: Ahmadi AA, Jahangardi K. Tehran: National Association of Parents and Teachers Publishing, 2010.

16) Fisher JR, Hammarberg K. Psychological and social aspects of infertility in men: an overview of the evidence and implications for psychologically informed clinical care and future research. Asian $\mathrm{J}$ Androl. 2012; 14(1): 121-9. doi: 10.1038/aja.2011.72, PMID: 22179515

17) Latifnejad Roudsari R, Allan HT. Women's Experiences and Preferences in Relation to Infertility Counselling: A Multifaith Dialogue. Int J Fertil Steril. 2011; 5(3):158-67. PMID: 25101160, PMCID: PMC4122831

18) Sudha G, Reddy KSN, Reddy KN, Reddy BKC. Emotional Distress in Infertile Couples: A Cross-. Cultural Study. Asia - Pacific Journal of Social Science. 2011; 3(1): 90-101.

19) McCarthy MP. Women's lived experience of infertility after unsuccessful medical intervention. J Midwifery Womens Health. 2008; 53(4): 319-24. doi:10.1016/j.jmwh.2007.11.004, PMID: 18586184

20) Mascarenhas MN, Cheung H, Mathers CD, Stevens GA. Measuring infertility in populations: constructing a standard definition for use with demographic and reproductive health surveys. Popul Health Metr. 2012; 10(1):17. doi: 10.1186/1478-7954-10-17, PMID: 22938182, PMCID: PMC3511253

21) Gibson DM, Myers JE. Gender and infertility: A relational approach to counseling women. J Counseling Dev. 2000; 78(4): 400-10. doi: 10.1002/j.1556-6676.2000.tb01923.x

22) Lee TY, Sun GH, Chao SC. The effect of an infertility diagnosis on the distress, marital and sexual satisfaction between husbands and wives in Taiwan. Hum Reprod. 2001; 16(8): 1762-7. doi:10.1093/humrep/16.8.1762. PMID: 11473979

23) Mohammadi Hosseini F, Farzadi L, Seyed Fatemi N. Tense factors and coping strategies in infertile women referring to Alzahra Training Clinical Center of Tabriz (1998). J Reprod Infertil. 2001; 2(3):27-34.

24) Inhorn MC. The Worms Are Weak.Male Infertility and Patriarchal Paradoxes in Egypt. Men and Masculinities. 2003; 5 (3):236-256, doi: 10.1177/1097184X02238525

25) Kormi Nouri R. Psycho-Social aspects of infertility. J Reprod Infertil. 2000; 1(2): 57-68.

26) Salmela-Aro K, Suikkari AM. Letting go of your dreams-Adjustment of child-related goal appraisals and deppresive symptoms during infertility treatment. J Res Personal. 2008; 22: (42): 988-1003. doi: 10.1016/j.jrp.2008.02.007

27) Younesi SJ, Salagegheh A. Body image in fertile and infertile women. J Reprod Infertil. 2001; 2(4): 14-21.

28) Abbasi Molid H, Reza Zadeh varaghchi J. Psychological Meta-Analysis of the Infertility Researches in Iran. IJOGI. 2012; 15 (13): 16-33.

29) Barua A, Pande R,Kurz K, Walia S, MacQuarrie K, Jain S. Addressing Gender-Based Constraints in Youth Reproductive Health: Experiences and Behaviors about Infertility among Young Couples in Rural Maharashtra, India. Foundation for Research in Health Systems (FRHS), International Center for Research on Women (ICRW).

30) Riahi ME 'Zarezade Mehrizi E. A study on the gender differences in psycho-social consequences of infertility: Infertile couples using Yazd' Infertility Center services. Womens Strategic Studies. 2012 ; 14 (56): 155-210.

31) Nilforooshan P, Ahmadi SA, Abedi MR, Ahmadi SM. Attitude towards infertility and its relation to depression and anxiety in infertile couples. J Reprod Infertil. 2006; 6(5): 546-52.

32) Fahami F, Hoseini Quchani S, EhsanpourS , Zargham A. Women's Lived Experiences of Female Infertility. IOG I. 2010; 4(30): 45-53. 
33) Sadeghin E, Heidarian-poor A, Abed F. Comparison of psychiatric problems in infertile men and women referring to infertility clinic of Hamadan Fatemyeh Hospital. Arak University of Medical Sciences Journal. 2006; 9 (2): 31-39.

34) Taghva N, Fathi Ashtiyani A. A Comparison between Psychological Features of Fertile and Infertile Individuals. Thought and Behavior in Clinical Psychology. 2009; 3(11): 45-54.

35) Tabong PT, Adongo PB. Infertility and childlessness: a qualitative study of the experiences of infertile couples in Northern Ghana. BMC Pregnancy Childbirth. 2013; 13:72. doi: 10.1186/1471-2393-13-72. PMID: 23517021, PMCID: PMC3610195

36) Mumtaz Z, Shahid U, Levay A. Understanding the impact of gendered roles on the experiences of infertility amongst men and women in Punjab. Reprod Health. 2013; 10:3. doi: 10.1186/1742-4755-10-3.

37) Burns N, Grove S K. The practice of nursing research Appraisal, Synthesis and Generation of evidence. 6 th ed. USA: Saunders Elsevier. 2009.

38) Holloway I, Wheeler S. Qualitative research in nursing and health care. 3th ed. Willy Blackwell.2010.

39) Savadzadeh S, madadzadeh N. Explanation of Emotional Feelings of Women with Infertility: A Qualitative Study. Journal of Ilam University of medical sciences. 2013; 21 (1): 16-24.

40) Lee GL, Hui Choi WH, Chan CH, Chan CL, Ng EH. Life after unsuccessful IVF treatment in an assisted reproduction unit: a qualitative analysis of gains through loss among Chinese persons in Hong Kong. Hum Reprod. 2009; 24(8): 1920-9. doi: 10.1093/humrep/dep091.

41) Dyer SJ, Abrahams N, Mokoena NE, van ZM der Spuy. You are a man because you have children': experiences, reproductive health knowledge and treatment seeking behaviour among men suffering from couple infertility in South Africa. Hum Reprod. 2004; 19(4): 960-67. doi: 10.1093/humrep/deh195

42) Choobforoushzade A, Kalantari M, Molavi H. The Effectiveness of Cognitive Behavioral Stress Management Therapy on Quality of Life in Infertile Women. 2011; 14 (1): 14-21.

43) Mohammadi MR, Abadi Farahani FK. Emotional and psychological problems of infertility and strategies to overcome them. J Reprod Infertil. 2001; 2(4): 33-9.

44) Loftus J, Namaste P. Expectant Mothers: Women's Infertility and the Potential Identity of Biological Motherhood. Qualitative Sociology Review.2011; 7 (1): 36-54.

45) Al-Homaidan HT. Depression among Women with Primary Infertility attending an Infertility Clinic in Riyadh, Kingdom of Saudi Arabia: Rate, Severity, and Contributing Factors. Int J Health Sci (Qassim). 2011; 5(2): 108-15. PMCID: PMC3521829

46) 46ok....Peterson BD. Examinig the congruence between couples' perceived infertility -related stress and its relationship to depression and marital adjustment in infertile men and women. MS Thesis in human development. Falls Church, Virginia .2000.

47) Aseffa F. Socio-cultural Perceptions of Infertility and their Implications: A Study of Women Experiencing Childlessness in South Gondar, Ethiopia. Master of Philosophy in Gender and Development, Faculty of Psychology, Department of Health Promotion and Development. 2011.

48) Pahlavani H, Malakouti K. Tehrani Nejad E. Stressors, their Coping Strategies, and Relation to Mental Health in Infertile Individuals. IJPCP. 2002; 7: 79-87.

49) Behdani F, Erfanian M, Hebrani P, Hojat SK. Prevalence of depression and related factors in infertile women. J Fundam Ment Health. 2004; 6(23-24): 141-6.

50) Abbasi-Shavazi MJ, Razeghi H, Behjati Z, M Akhondi. Attitudes of infertile women towards gamete donation: A case study in Tehran. J Reprod Infertil. 2006; 7(2): 139-48.

51) Younesi SJ, Akbari-Zardkhaneh S, Behjati Ardekani Z. Evaluating stigma among infertile men and women in Iran. J Reprod Infertil. 2006; 6(5): 531-45.

52) Faal Kalkhoran L, Bahrami H, Farrokhi NA, Zeraati H, Tarahomi M. Comparing Anxiety, Depression and Sexual Life Satisfaction in Two Groups of Fertile and Infertile Women in Tehran. J Reprod Infertil. 2011; 12(2): 157-62. 